\title{
Prevalence of thyroid antibodies in Shiraz, Iran, an area with iodine deficiency
}

\author{
Ali A. Khaleeli \\ M.B., M.R.C.P. \\ Department of Human Metabolism, University College Hospital, London
}

\begin{abstract}
Summary
The prevalence of thyroid antibodies was $2 \%$ among 53 healthy Shirazi volunteers, $3 \%$ among 30 consecutive patients with goitre, $41 \%$ among 17 patients with thyrotoxicosis and $67 \%$ among 18 consecutive patients with myxoedema. A surprising finding was that in a sub-group of 9 of the latter, a high incidence of diabetes $(55 \%)$ was found and when both diseases coexisted, the prevalence of thyroid antibodies was $80 \%$ compared with $67 \%$ with myxoedema alone.

Serum cholesterol was marginally lower in the goitre than the control group $(P, 0.05-0.025)$ but when females alone were compared there was no significant difference. It was also lower in the thyrotoxic group $(P, 0.0025)$ and higher in the myxoedema group $(P, 0.0025)$. Serum triiodothyronine was lower in the goitre group than the controls $(P, 0.0005)$ but again, when females alone were considered, this difference lessened $(P, 0.025-0.0125)$. Serum thyroxine and thyroid stimulating hormone levels showed no significant differences in the goitre and control groups.
\end{abstract}

\section{Introduction}

Iodine deficiency in Fars province in southern Iran shows variable degrees of severity. In Ardekan, a small town receiving its water from one main spring, the low iodine content and the high prevalence of goitre is known, although cretinism and deaf mutism are rare, suggesting in relative terms that iodine deficiency is only moderate (Delange et al., 1972b).

Caughey stated that Shiraz was an area endemic for iodine deficiency and that the iodine deficiency was mild (Caughey, 1971). In his study of 1440 teenage girls, $85 \%$ had a goitre, although in most it was small. Water with an iodine content below 2.5 $\mu \mathrm{g} / \mathrm{l}$ almost always results in goitre (Roche and Lissitzky, 1960), and values above $25 \mu \mathrm{g} / \mathrm{l}$ usually protect against it (Malamos et al., 1971). Caughey also found that in $\mathbf{3 3}$ patients with goitre the mean urinary iodide was $25 \mu \mathrm{g} / \mathrm{g}$ creatinine. OlwenWilliams and Hammick (1974) quote Caughey as showing that the drinking water in Shiraz contained $12 \mu \mathrm{g} / \mathrm{l}$ of iodine. Both these values correspond to those found in areas of mild to moderate iodine deficiency (Ibbertson, 1979). As areas of mild iodine deficiency are more likely to reveal other factors, such as autoimmune thyroiditis in the pathogenesis of goitre, Shiraz was chosen as the venue for the study. Furthermore, if autoimmune thyroiditis is prevalent, one might expect a high incidence of positive thyroid antibodies in newly found patients with myxoedema and thyrotoxicosis, as in the United Kingdom and elsewhere (Doniach, Hudson and Roitt, 1960; Roitt and Doniach, 1960). It was thus decided to estimate the incidence of thyroid antibodies in health, goitre, myxoedema and thyrotoxicosis in Shiraz.

\section{Patients and methods}

A group of 53 healthy volunteers, comprising 28 males and 25 females living and working in the university town of Shiraz acted as controls. None of these had a palpable or visible goitre. Thirty consecutive patients with diffuse goitre, 28 of which were female and 2 male and all of whom were clinically euthyroid comprised the goitre group. The term goitre here denotes both a visible and palpable swelling of the thyroid gland moving freely upwards on swallowing. Twelve of these had thyroid scans showing diffuse enlargement and one patient previously shown to have a cold nodule and a further one a multinodular goitre were excluded. Eighteen consecutive patients with primary hypothyroidism and 17 with thyrotoxicosis due to diffuse thyromegaly, in 11 confirmed by thyroid scans, acted as the other 2 groups. The term primary hypothyroidism is defined as underactivity of the thyroid gland resulting in low circulating thyroid hormones and a raised serum TSH level. The term is used interchangeably with myxoedema in the text except that when the latter is used describing the Shirazi patients the presence of non-pitting oedema is implied. Thyrotoxicosis is defined as the clinical state resulting from excessive thyroid hormone activity and associated with raised 
circulating levels of thyroxine $\left(\mathrm{T}_{4}\right)$ and/or triiodothyronine $\left(\mathrm{T}_{3}\right)$. Where thyroid scans were not done (e.g. 18 of the patients with goitre, 6 with thyrotoxicosis) this was because radioiodine was unfortunately unavailable owing to the political upheaval occurring in Iran.

All subjects gave verbal and, where possible, written consent. Each subject was assessed regarding thyroid status, size of goitre and where possible, aetiology. Associated clinical conditions were noted. Blood was taken from an antecubital vein and the serum divided into 2 portions. The first was stored at $4^{\circ} \mathrm{C}$ until its despatch to Charing Cross Hospital, London, where thyroid autoantibodies were estimated within 10 days. An indirect immunofluorescent technique, using Coon's reagent diluted to 1 to 10 and multiblocks including human thyroid gland, was used. This was conjugated with antihuman IgG and examined for microsomal antibodies using a fluorescent microscope. The result was graded as negative or,+++ or +++ positive. No actual titres were performed except in 2 representative patients with weakly positive $(+)$ results. These included one patient with myxoedema (titre 1 in $80^{2}$ ), and one with thyrotoxicosis (titre 1 in $40^{2}$ ). All weak positive results are indicated in Table 1 but in general most positives were strongly so at ++ or more and these correspond in the authors' laboratory to titres of 1 in $80^{2}$ or more.

The remaining portions were stored at $-20^{\circ} \mathrm{C}$ until estimations of serum $\mathrm{T}_{4}, \mathrm{~T}_{3}$, TSH and cholesterol were done. The former 3 were estimated using a radioimmunoassay procedure with either Amersham (Radiochemical Centre, Amersham) or Phadebas Kits either in Shiraz or London. The sera were randomly distributed in roughly equal numbers between the 2 centres. Serum cholesterol was measured using a cholesterol oxidase/phenol/4-aminophenazone method as supplied by B.C.L. Ltd on an AA II autoanalyser.

A sub-group of 9 myxoedematous patients had blood glucose measurements using a glucose oxidase method. Either single fasting readings were used when these were clearly abnormal (5 patients) or a standard oral $50-\mathrm{g}$ glucose tolerance test performed in the rest. The term diabetes here is defined either as a fasting blood sugar above $\mathbf{7 \cdot 2} \mathrm{mmol} / \mathrm{l}$, or when the 50-g glucose tolerance test is used, as a peak level exceeding $8.9 \mathrm{mmol}$ or a level at $2 \mathrm{hr}$ exceeding 6.7 mmol.

Radioactive iodine uptakes using ${ }^{131} I$ at 2 and 24 $\mathrm{hr}$ were performed on 11 patients with goitre, and 11 with thyrotoxicosis had thyroid scans done.

\section{Results}

These are summarized in Table 1 . There were no significant differences between the goitre and control groups in the mean serum $\mathrm{T}_{4}, \mathrm{TSH}$, cholesterol of incidence of thyroid antibodies. Only one patient i each of these groups had weakly positive antibodies and unfortunately no titres were possible. Anti:bodies were present in $67 \%$ of the myxoedema an $41 \%$ of the thyrotoxic group. Both these groups ip cluded one patient each with weakly positive ante bodies in addition to the 2 previously cited, the res mainder showing ++ or +++ readings. The meam serum $T_{3}$ was significantly lower in the goitre group than in the controls. Serum cholesterol was signi? ficantly lower in the thyrotoxic group and higher $i \vec{\Phi}$ the myxoedema group, but the mean value of $6 \cdot \underline{\underline{a}}$ $\mathrm{mmol} / \mathrm{l}$ would have been considered at the uppefs limit of normal for a British population.

The ranges are also tabulated and 2 patients had $\frac{0}{3}$ raised TSH level in the goitre group despite appeaEing clinically euthyroid and having normal $\mathbf{T}_{4}$ and $\mathrm{T}_{3}$ levels. However, TSH levels have been found to be high in endemic areas despite the patient appearo ing clinically euthyroid (Chopra, Herschmann any Hornabrook, 1975; Patel et al., 1973; Delangę Herschmann and Ermans, 1971). Here the raised TSH levels may reflect a compensatory mechanisro by the body to iodine deficiency rather than implye ing a failing thyroid as it does in autoimmune thyroiditis (AIT) (Ibbertson, 1979). Thus these patients are included in the goitre group. One pationge with goitre had a low $T_{4}$ level and a low $T_{3}$ level but her serum TSH was at the upper limit of norng her cholesterol was only 3.9 and she also hat weakly positive antibodies. This patient might have had mild hypothyroidism but clinically she appeare euthyroid and there was no change over 10 months? Low thyroglobulin levels might have explained he $\overrightarrow{5}$ low serum $T_{4}$ and $T_{3}$ but neither a free $T_{4}$ nor $\$$ TRH test to exclude hypothyroidism could be done?

Radioiodine studies showed a diffuse goitre in a the subjects in the goitre and thyrotoxic groups thato were studied and all the patients with thyrotoxicosis. had high uptakes. Evidence for iodine deficiency was present in the majority of patients with goitre whohad uptake studies and 8 out of 11 had raised up? takes at $24 \mathrm{hr}, 5 \mathrm{had}$ raised levels at $2 \mathrm{hr}$ and the re maining 6 high normal readings (14-20\%).

The commonest cause for primary hypothyroidismp found was autoimmune thyroiditis and 11 patients: had positive antibodies alone $(61 \%)$, one had hadু surgery and antibodies, one surgery and radioactive iodine, and 2 had had radioactive iodine alone. In the remaining 3, one had previously been treated for Graves' disease with drugs alone and one was cretin.

A sub-group of 9 myxoedematous patients $(50 \%$ had blood glucose estimations. In 5, fasting blood ${ }^{+}$ glucose was raised at $8.8,14,17,11$ and $7.6 \mathrm{mmol} / \mathrm{L}$ using venous blood. Some of these patients were्ष 


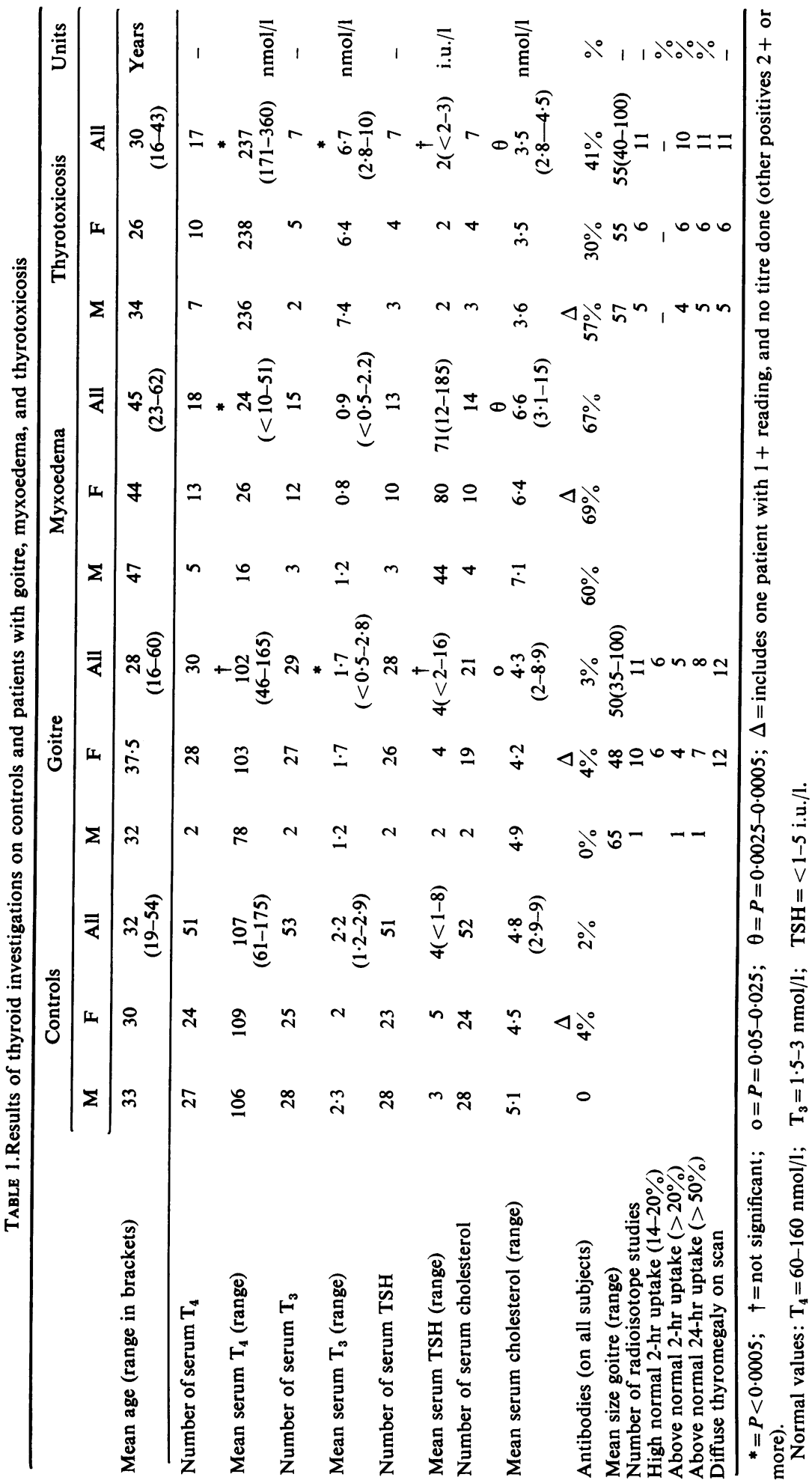


symptomatic but none was insulin dependent. Of these, 3 were known diabetics, and in 2 the diabetes had preceded the myxoedema. One other patient had a borderline glucose tolerance test (fasting, 30min, $60-\mathrm{min}$, and 120 -min readings being $5 \cdot 25,7 \cdot 0$, $6.5,6.5 \mathrm{mmol} / \mathrm{l})$. The remaining 3 patients had normal glucose tolerance tests. The incidence of diabetes was $55 \%$. The prevalence of thyroid antibodies in the diabetic myxoedematous group was $80 \%$ and, if the borderline patient was included, $83 \%$, whereas the prevalence of antibodies in the myxoedema alone was $66 \cdot 6 \%$.

\section{Discussion}

Both the control and goitre groups showed a low incidence of thyroid antibodies. In the former group a $2 \%$ prevalence is much lower than a $7 \%$ prevalence in a northern English community where there is no iodine deficiency, but in which microsomal antibodies were also measured (Tunbridge et al., 1977). In the latter survey and in others (Couchman, Wigley and Prior, 1970) the prevalence of antibodies rose with age in women and there was a 4-fold increase in women at all ages. As the control group had a low mean age and a slight male preponderance, the lower incidence is partially explained. Nevertheless, despite the small numbers (partly because the study could not be extended owing to the political upheaval in Iran) this study failed to show that AIT plays a significant role in the pathogenesis of goitre. This is despite the fact that both the myxoedema and thyrotoxicosis groups reflected a high prevalence rate of AIT. The myxoedema group was on average 12.5 years older than the control age group, and was composed mainly of women. One might expect therefore a slightly increased incidence of antibodies. However, the diferences are more than can be explained by this. Furthermore, if all the patients aged 55 years or more are excluded from the myxoedema group, the mean age out of 12 patients becomes 38 years, but the incidence of antibodies actually rises to $83 \%$. Iodine deficiency alone might be the explanation for goitre, and the radioactive uptake studies done supported its presence as did the high female to male ratio $(14: 1)$ in the goitre group, reflecting mild deficiency. Alternatively, women would be expected to complain of goitre more frequently than would men, for cosmetic reasons. Other factors, such as unrecognized goitrogens were not tested in this study.

An unexpected finding was the high incidence of diabetes $(55 \%)$ in the myxoedema group. Type I or insulin-dependent diabetes has been known to be associated with other organ specific autoimmune diseases for some time, especially thyroid disease and pernicious anaemia (Cudworth, 1978; Editorial,
1976). More recently, type I diabetes has been classi乞 fied into IA and IB sub-groups (Bottazzo and Doniz ach, 1976) according to the temporary or more perฉ manent persistence of pancreatic islet cell antibodies. which have recently been demonstrated (Bottazzo $\overrightarrow{\overrightarrow{\mathrm{e}}}$ Florin-Christensen and Doniach, 1974; MacCuist? et al., 1974). Also, type I but not type II (insuliro independent) diabetes has been shown to occute more frequently in HLA haplotypes B8 and BW15 and when both exist the risk is additive (Nerup et al. 0 1974). More recently still, type I diabetes occurring in association with myxoedema has been shown to have a higher association with the haplotype HLAB8 than type I diabetes alone (Bottazzo et al. $\vec{\omega}$ 1978). However, the present patients were type if diabetics and there is barely any increase found iff these 2 diseases occurring together except for that they are both common diseases and are more likely to be present as age advances. There was a slightlys higher mean age group when both were present $(5 \%$ years) compared to the myxoedema group excluding the diabetics (41 years) but this would never explain the very high incidence. Furthermore, the diabeticmyxoedematous sub-group had a higher incidence of antibodies against the thyroid gland, although age differences might have partly accounted for this Nevertheless some genetic influence appears to be operating in the Shirazi diabetic myxoedemate 150 patients and, when more pressing problems hare been overcome, a study of their HLA haplotyps: might be worth-while.

Finally, the mean serum $T_{3}$ was significantly lowero in the goitre than in the control group. However: there was a marked (14:1) female preponderance in the goitre group and when only the females in both $\overrightarrow{\vec{F}}$ groups were compared the difference in the mean 3 serum $\mathrm{T}_{3}$ lessened considerably $(P, 0.025-0.0125)$. One might in fact have expected serum $T_{3}$ levels tơ be higher in the goitre group, as in other endemic areas when the $T_{4}$ is low the patient remains euthy- 3 . roid because serum $T_{3}$ levels are normal or even: elevated (Delange, Camus and Ermans, 1972a). When patients with a high TSH in these areas haveo been given $T_{3}$ therapy, the high TSH levels have not always come down as expected, even thougho serum levels of $T_{3}$ have been elevated (Saberi and $>$ Utiger, 1974). The explanation for the present patients' low $T_{3}$, however, is not obvious.

\section{Acknowledgments}

I am indebted particularly to Dr P. B. S. Fowler and Dr $\frac{\omega}{\sigma}$ A. Zadeh, without whom this study would not have been possible. I would also like to thank my colleagues, in particular Dr M. Shahmanesh in Shiraz who referred me many $\frac{\complement}{\mathbb{D}}$ patients; Dr P. Wise, the residents in Shiraz University, Miss F. Rahaman of the Microbiology Department, and the staff $\square$ of the Endocrine and Chemical Pathology Laboratories, $\vec{O}$ Charing Cross Hospital. 


\section{References}

Bottazzo, G. F., Cudworth, A. G., Moul, D. J., Doniach, D. \& Festenstein, H. (1978) Evidence for a primary autoimmune type of diabetes mellitus. British Medical Journal, 2, 1253.

Bottazzo, G.F. \& Doniach, D. (1976). Pancreatic autoimmunity and HLA antigens. Lancet, ii, 800.

Bottazzo, G.F., Florin-Christensen, A. \& Doniach, D. (1974) Islet cell antibodies in diabetes mellitus with autoimmune polyendocrine deficiencies. Lancet, ii, 1279.

CaugheY, J.E. (1971) The spectrum of iodine malnutrition and suggested management. Pahlavi (now Shiraz) Medical Journal, 2, 132.

Chopra, I.J., Herschmann, J.M. \& Hornabrook, R.W. (1975) Serum thyroid hormone and thyrotrophin levels in subjects from endemic goitre regions of New Guinea. Journal of Clinical Endocrinology and Metabolism, 40, 326.

Couchman, K.G., Wigley, R.D. \& Prior, I.A.M. (1970) Autoantibodies in the Carterton Population Survey (the prevalence of thyroid and gastric antibodies, antinuclear and rheumatoid factors in a probability based population sample). Journal of Chronic Diseases, 23, 45.

Cudworth, A.G. (1978) Type 1 diabetes. Diabetologia, 14, 281.

Delange, F., Camus, M. \& Ermans, A.M. (1972a) Circulating thyroid hormones in endemic goitre. Journal of Clinical Endocrinology and Metabolism, 34, 891.

Delange, F., Costa, A., Ermans, A.M., Ibbertson, H.K., Querido, A. \& Stanbury, J.B. (1972b) A survey of the clinical and metabolic patterns of endemic cretinism. In: Human Development and the Thyroid Gland, Relation to Endemic Cretinism, p. 175. Plenum. New York.

Delange, F., Herschmann, J.M. \& Ermans, A.M. (1971) Relationship between serum thyrotrophin levels, the prevalence of goitre and the pattern of iodine metabolism in the Idijiwi islands. Journal of Clinical Endocrinology and Metabolism, 33, 261.

Doniach, D., Hudson, R.V. \& RoItT, I.M. (1960) Auto- immune thyroiditis: clinical studies. British Medical Journal, 1, 365.

EDITORIAL (1976) Diabetes mellitus and autoimmunity. Lancet, ii, 1124.

IBBERTSON, H.K. (1979) Endemic goitre and cretinism. Clinics in Endocrinology and Metabolism, 8, 97.

MacCuish, A.C., Barnes, E.W., Irvine, W.H. \& Duncan, L.J.P. (1974) Autoantibodies to pancreatic islet cells in insulin dependent diabetes with coexistent autoimmune disease. Lancet, ii, 1529.

Malamos, B., Koutras, D.A., Rigopoulos, G.A., Papapetrou, P.D., Gougas, E., Kelperi, H., Moraitopoulos, C., Davi, E. \& Leonardopoulos, J. (1971) Endemic goitre in Greece: some new epidemiological studies. Journal of Clinical Endscrinology, 32, 130.

Nerup, J., Platz, P., Anderson, O.O., Christy, M., Lyngsoe, J., Poulsen, J.E., Ryder, L.P., Thomson, M., Staub Nielsen, L. \& SvejgaArd, A. (1974) HLA antigens and diabetes mellitus. Lancet, ii, 864.

Olwen-Williams, J. \& Hammick, J.W. (1974) Thyroid function tests in Shiraz, Iran. Pahlavi (now Shiraz) Medical Journal, 5, 14.

Patel, Y.C., Pharoah, P.O.D., Hornabrook, R.W. \& HeTZEL, B.S. (1973) Serum triiodothyronine, thyroxine and thyroid stimulating hormone in endemic goitre: a comparison of goitrous and non-goitrous subjects in New Guinea. Journal of Clinical Endocrinology and Metabolism, 37, 783.

Roche, J. \& LissitzKy, S. (1960) Etiology of Endemic Goitre. WHO Monograph Series, 44, 351.

RoITT, I.M. \& DoniACH, D. (1960) Thyroid autoimmunity. British Medical Bulletin, 16, 152.

SABERI, M. \& Utiger, D. (1974) Serum thyroid hormone and thyrotrophin concentrations during thyroxine and triiodothyronine therapy. Journal of Clinical Endocrinology and Metabolism, 39, 923.

Tunbridge, W.M.G., Evered, H., Hall, R., Appleton, D. Brewis, M., Clark, F., Grimley Evans, J., Young, E., BIRD, T. \& SMITH, P.A. (1977) The spectrum of thyroid disease in a community: the Whickham Survey. Clinical Endocrinology, 7, 481. 